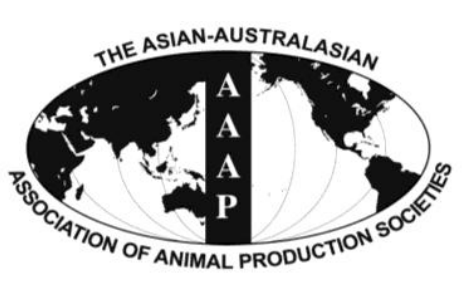

Open Access

Asian Australas. J. Anim. Sci.

Vol. 28, No. 1 : 135-142 January 2015

http://dx.doi.org/10.5713/ajas.14.0066

www.ajas.info

pISSN 1011-2367 elSSN 1976-5517

\title{
Immune Responses in Broiler Chicks Fed Propolis Extraction Residue-supplemented Diets
}

\author{
C. Eyng*, A. E. Murakami, T. C. Santos, T. G. V. Silveira ${ }^{1}$, R. B. Pedroso ${ }^{1}$, and D. A. L. Lourenço \\ Department of Animal Science, Universidade Estadual de Maringá, Maringá, SP 87020-900, Brazil
}

\begin{abstract}
This study was conducted to evaluate the effect of inclusion of propolis extraction residue in the feed of broilers from 1 to $21 \mathrm{~d}$ of age on phagocytic activity of macrophages, cutaneous basophil hypersensitivity response to phytohemagglutinin, antibody production against Newcastle disease, lymphoid organ weight and hematological profile and to determine the optimal level of inclusion. 120 chicks, reared in metabolism cages until 21 days of age, were distributed in a completely randomized design, with five treatments $(0 \%, 1 \%, 2 \%, 3 \%$, and $4 \%$ of propolis residue) and six replications. The relative weight of thymus and monocyte percentage were affected by propolis residue, with a quadratic response $(\mathrm{p}<0.05)$ and lowest values estimated at $2.38 \%$ and $2.49 \%$, respectively. Changes in relative weight of cloacal bursa and spleen, percentage of lymphocyte, heterophil, basophil, eosinophil, and heterophil:lymphocyte ratio, antibody production against Newcastle disease, phagocytic activity of macrophages and the average number of phagocytosed erythrocytes were not observed. The nitric oxide production with regard to positive control (macrophages+erythrocytes) decreased linearly $(\mathrm{p}<0.05)$ with increased doses of propolis residue. The remaining variables of nitric oxide production (negative control macrophages, and difference between the controls) were not affected by propolis residue. The cutaneous basophil hypersensitivity response to phytohemagglutinin as determined by the increase in interdigital skin thickness exhibited a quadratic response ( $<<0.05$ ), which predicted a lower reaction response at a dose of $2.60 \%$ of propolis residue and highest reaction response after 43.05 hours of phytohemagglutinin injection. The inclusion of $1 \%$ to $4 \%$ of propolis extraction residue in broiler diets from 1 to 21 days of age was not able to improve the immune parameters, despite the modest changes in the relative weight in thymus, blood monocyte percentage, nitric oxide concentration, and interdigital reaction to phytohemagglutinin. (Key Words: Antibody, Cutaneous Basophil Hypersensitivity, Humoral Immune Response, Macrophages, Propolis Residue)
\end{abstract}

\section{INTRODUCTION}

With regard to maximum feed efficiency and production, for decades, the poultry industry has been using antibiotics in sub-therapeutic doses in diets. However, bacterial resistance in humans has been related to abusive use of these additives in animal diets (Apata, 2009). Based on this fact and combined with public pressure, many countries have banned these additives in feed supplementation (Casewell et al., 2003).

Propolis is a natural resinous mixture produced by

\footnotetext{
* Corresponding Author: C. Eyng. Tel: +55-67-81642888, E-mail: cinthiaeyng@hotmail.com

${ }^{1}$ Department of Clinical Analysis and Biomedicine,Universidade Estadual de Maringá/UEM, Maringá, PR 87020-900, Brazil.

Submitted Jan. 27, 2014; Revised Mar. 11, 2014; Accepted Aug. 23, 2014
}

honey bees from substances collected from many plants sources (Salatino et al., 2011). Due to the many biological activities of propolis, such as antimicrobial, antiinflammatory, antioxidant and immunostimulatory, which are attributed to its chemical composition, including flavonoids, aromatic acids, diterpene acids and phenolic compounds (Lofty et al., 2006; Trusheva et al., 2006), this product has prompted worldwide research as an alternative to antibiotics. In this context, researchers have been observed the immunoregulatory effect of propolis on production of factors involved in inflammation, such as cytokines, prostaglandins, chemokines, and others (Hu et al., 2005; Kosalec et al., 2005). In fact, studies have shown that propolis is able to cause immunomodulatory effects in animals, influencing the activation of macrophages, antibody synthesis and the weight of lymphoid organs (Orsi 
et al., 2000; Ziaran et al., 2005; Çetin et al., 2010; Fischer et al., 2010).

Considering the complex mixture of propolis which includes resins, waxes, essential oils, pollen and various organic compounds, it is necessary to extract the desired chemical components from the raw material (Wagh, 2013). For use in human medicine, a mixture of crude propolis is submitted to extraction and purification processes (Shalmany and Shivazad, 2006), using solvents that are able to extract the biologically active compounds from the solid portion (Schnitzler et al., 2010). However, these processes produce a large amount of residue, without any commercial value. Thereby, the possibility that this residue, when added to animal diets, may also cause modulatory effects on immune function has arisen; moreover, it is suggested as an appropriate way of disposal to avoid any impact on the environment.

Thus, the objective of the study herein was to evaluate the effect of inclusion of propolis extraction residue in the feed of broilers from 1 to $21 \mathrm{~d}$ of age on phagocytic activity of macrophages, cutaneous basophil hypersensitivity response to phytohemagglutinin, antibody production against Newcastle disease, lymphoid organ weight and hematological profile and to determine the optimal level of inclusion.

\section{MATERIAL AND METHODS}

The protocol for this experiment was approved and birds were cared according to the guidelines of the Universidade Estadual de Maringá (Maringá, Paraná, Brazil).

A total of 120 1-day-old male Cobb-Vantress chicks were raised in metabolism cages until 21 days of age. The experimental design included broilers randomly assigned to five treatments $(0 \%, 1 \%, 2 \%, 3 \%$, and $4 \%$ of propolis residue in the feed). The experimental units were repeated six times with four birds each. The experimental diets were formulated to meet the nutritional requirements proposed by Rostagno et al. (2005), for the 1-to-7-day-old and the 8-to21-day-old age groups (Table 1). The propolis residue used was acquired in Maringá, State of Paraná, Brazil, air dried and stored at $2^{\circ} \mathrm{C}$ to $8^{\circ} \mathrm{C}$ until utilization. The total polyphenols in the propolis residue was determined according to Singleton and Rossi (1965) and Pierpoint (2004) and the total flavonoids content was evaluated using

Table 1. Ingredients and nutrient composition of the experimental diets

\begin{tabular}{|c|c|c|c|c|c|c|c|c|c|c|}
\hline \multirow{2}{*}{ Items } & \multicolumn{5}{|c|}{1 to $7 \mathrm{~d}$} & \multicolumn{5}{|c|}{8 to $21 \mathrm{~d}$} \\
\hline & Control & $1 \%$ & $2 \%$ & $3 \%$ & $4 \%$ & Control & $1 \%$ & $2 \%$ & $3 \%$ & $4 \%$ \\
\hline \multicolumn{11}{|l|}{ Ingredients (\%) } \\
\hline Corn & 56.80 & 54.70 & 52.60 & 50.50 & 48.40 & 59.68 & 57.58 & 55.48 & 53.38 & 51.29 \\
\hline Soybean meal $45 \%$ & 36.84 & 37.24 & 37.63 & 38.03 & 38.43 & 34.19 & 34.59 & 34.98 & 35.38 & 35.77 \\
\hline Soybean oil & 1.85 & 2.56 & 3.27 & 3.97 & 4.68 & 2.16 & 2.87 & 3.57 & 4.28 & 4.99 \\
\hline Limestone & 0.92 & 0.92 & 0.91 & 0.91 & 0.90 & 0.88 & 0.88 & 0.87 & 0.87 & 0.86 \\
\hline Dicalcium phosphate & 1.94 & 1.94 & 1.95 & 1.95 & 1.96 & 1.80 & 1.80 & 1.81 & 1.81 & 1.82 \\
\hline $\mathrm{NaCl}$ & 0.40 & 0.40 & 0.40 & 0.40 & 0.40 & 0.40 & 0.40 & 0.40 & 0.40 & 0.40 \\
\hline Propolis extraction residue & - & 1.00 & 2.00 & 3.00 & 4.00 & - & 1.00 & 2.00 & 3.00 & 4.00 \\
\hline DL-met $98 \%$ & 0.35 & 0.36 & 0.36 & 0.36 & 0.36 & 0.24 & 0.24 & 0.25 & 0.25 & 0.25 \\
\hline L-lys $\mathrm{HCl} 78.5 \%$ & 0.35 & 0.34 & 0.34 & 0.33 & 0.32 & 0.19 & 0.18 & 0.18 & 0.17 & 0.16 \\
\hline L-thr $98 \%$ & 0.15 & 0.15 & 0.15 & 0.14 & 0.14 & 0.05 & 0.05 & 0.05 & 0.05 & 0.05 \\
\hline Supplement minerals and vitamins ${ }^{1}$ & 0.40 & 0.40 & 0.40 & 0.40 & 0.40 & 0.40 & 0.40 & 0.40 & 0.40 & 0.40 \\
\hline Total & 100 & 100 & 100 & 100 & 100 & 100 & 100 & 100 & 100 & 100 \\
\hline \multicolumn{11}{|l|}{ Calculated composition } \\
\hline $\mathrm{CP}(\%)$ & 22.04 & 22.04 & 22.04 & 22.04 & 22.04 & 20.79 & 20.79 & 20.79 & 20.79 & 20.79 \\
\hline $\mathrm{ME}(\mathrm{kcal} / \mathrm{kg})$ & 2.950 & 2.950 & 2.950 & 2.950 & 2.950 & 3.000 & 3.000 & 3.000 & 3.000 & 3.000 \\
\hline $\mathrm{Ca}(\%)$ & 0.939 & 0.939 & 0.939 & 0.939 & 0.939 & 0.884 & 0.884 & 0.884 & 0.884 & 0.884 \\
\hline Avaiable P (\%) & 0.470 & 0.470 & 0.470 & 0.470 & 0.470 & 0.442 & 0.442 & 0.442 & 0.442 & 0.442 \\
\hline Digestible Met+cys (\%) & 0.944 & 0.944 & 0.944 & 0.944 & 0.944 & 0.814 & 0.814 & 0.814 & 0.814 & 0.814 \\
\hline Digestible Lys (\%) & 1.330 & 1.330 & 1.330 & 1.330 & 1.330 & 1.146 & 1.146 & 1.146 & 1.146 & 1.146 \\
\hline Digestible Thr (\%) & 0.865 & 0.865 & 0.865 & 0.865 & 0.865 & 0.745 & 0.745 & 0.745 & 0.745 & 0.745 \\
\hline Digestible Trp (\%) & 0.240 & 0.240 & 0.240 & 0.240 & 0.240 & 0.230 & 0.230 & 0.230 & 0.230 & 0.230 \\
\hline
\end{tabular}

$\mathrm{CP}$, crude protein; ME, metabolizable energy.

1 Vitamin mixture (content per $\mathrm{kg}$ of diet): vitamin A (retinylacetate), 11,667 IU; vitamin $\mathrm{D}_{3}$ (cholecalciferol), 2,333 IU/kg; vitamin E (DL-atocopherylacetate), $35 \mathrm{IU}$; vitamin $\mathrm{K}_{3}$ (menadione dimethylpyrimidinol), $1.73 \mathrm{IU}$; vitamin $\mathrm{B}_{1}$ (thiamine mononitrate), 1.63 mg; vitamin $\mathrm{B}_{2}$ (riboflavin), $5.33 \mathrm{mg}$; vitamin $\mathrm{B}_{12}$ (cyanocobalamin), $0.02 \mathrm{mg}$; niacin (niacinamide), $35.93 \mathrm{mg}$; calcium pantothenate, $12.67 \mathrm{mg}$; folic acid, $0.80 \mathrm{mg}$; D-biotin, 0.10 $\mathrm{mg}$. Mineral mixture (content per kg of diet): Fe (iron sulfate monohydrate), $50.40 \mathrm{mg}$; $\mathrm{Cu}$ (cooper sulfate pentahydrate), $12.29 \mathrm{mg}$; (calcium iodate), 0.99 mg; Zn (zinc oxide), 50.40 mg; Mn (manganous oxide), 60 mg; Se (sodium selenite), $0.24 \mathrm{mg}$; Co (cobalt sulfate), $0.20 \mathrm{mg}$. 
the aluminum chloride colorimetric methods (Woisky and Salatino, 1998).

All broilers were vaccinated against Newcastle disease at 14 days of age and blood sampling was carried out at 21 days of age on six birds per treatment. After clotting, blood was reserved for Newcastle antibody production measurements. Serum samples were analyzed by an enzyme-linked immunosorbent assay (ELISA) using Flock Check Idexx (IDEXX) ELISA Test Kit. The assay was performed according to the instructions provided by the company. Serum samples were diluted (1:500) into test tubes. One hundred microliters of diluted serum samples were dispensed in duplicate to appropriate wells of Newcastle Disease antigen coated microtiter plates and incubated for $30 \mathrm{~min}$ at room temperature. Liquid content of all wells was aspirated and then wells were washed six times with $350 \mu \mathrm{L} /$ well of distilled water. After that, $100 \mu \mathrm{L}$ of goat anti-chicken/turkey horseradish peroxidase conjugated second antibody was added for $30 \mathrm{~min}$ at room temperature. After washing the wells six times, $100 \mu \mathrm{L}$ of 3,3,5,5-tetramethyl-benzidine solution was added and incubated for $15 \mathrm{~min}$ at room temperature. The reaction was stopped by adding $100 \mu \mathrm{L}$ of $2 \mathrm{M} \mathrm{H}_{2} \mathrm{SO}_{4}$ to each well. The optical density of the plate was read by an automatic ELISA plate reader at $630 \mathrm{~nm}$.

At 21 days of age, six broilers per treatment, with a representative weight (average $\pm 5 \%$ ) were selected for analysis of hematological profile and relative weight (\% of live weight) of the lymphoid organs (cloacal bursa, thymus and spleen). Blood-smear stains using May GrunwaldGiemsa method were prepared to determine the hematological profile. One hundred white blood cells were examined per bird using an optical microscope and an immersion objective, and the percentage of each of five basic leukocytes (lymphocytes, heterophils, eosinophils, monocytes, and basophils) was calculated (Lucas and Jamroz, 1961). The heterophil:lymphocyte ratio was calculated dividing heterophil by lymphocyte percentages.

Six birds from each treatment were also selected at 21 days of age to evaluate the immune response by a cutaneous basophil hypersensitivity (CBH) test using phytohemagglutinin PHA-M (Invitrogen) (Corrier and Deloach, 1990). Phytohemagglutinin at $0.1 \mathrm{~mL}$ was intradermally injected between the third and fourth interdigital folds of each animal's right foot. The same volume of saline solution was applied to the left foot as a negative control. Thickening of the skin on both feet was measured, using a digital caliper, before inoculation, and 12, 24, 48, and 72 hours after inoculation. The results were obtained by calculating the difference between phytohemagglutinin response and control response at each different time point.

Five birds per treatment were chosen randomly to evaluate the phagocytic activity of abdominal macrophages, according to the methodology described by Qureshi et al. (1986). At 21 days of age, a 3\% Sephadex G-50 (Sigma) solution $(0.9 \%$ saline solution) was injected at $1 \mathrm{~mL} / 100 \mathrm{~g}$ of body weight into each animal's peritoneal cavity 42 hours prior to collection. The birds were slaughtered by cervical dislocation; each bird's abdomen was cleaned (neutral detergent) and sanitized $(70 \%$ alcohol $)$ and inoculated with $20 \mathrm{~mL}$ of sterile heparinized phosphate buffered saline $(0.5 \mathrm{U} / \mathrm{mL}$ Liquemine; Roche). Approximately $15 \mathrm{~mL}$ of the abdominal liquid was collected and immediately conditioned in plastic tubes on ice. The collected material was centrifuged at 1,500 rpm/10 min, and the pellet was resuspended in $1.5 \mathrm{~mL}$ of Roswell Park Memorial Institute (RPMI) 1640 (Sigma, São Paulo, $\mathrm{SP}, \mathrm{Brazil})$. A total of $150 \mu \mathrm{L}$ of this suspension was added to each well of the culture plate with a $13-\mathrm{mm}$ diameter glass coverslip. After an hour in the incubator at $37^{\circ} \mathrm{C}$ with $5 \% \mathrm{CO}_{2}$, each well was washed with RPMI 1640 solution to remove the non-adhered cells. Next, $200 \mu \mathrm{L}$ of sheep erythrocytes was added (suspension of $3 \%$ red blood cells in RPMI 1640), and the mixture was incubated again for one hour. After incubation, each well was washed with RPMI 1640 and each glass coverslip was stained using a commercial kit (Panótico Rápido LB, Laborclin, Pinhais, Paraná, Brazil). After the coverslips fixation process, 200 macrophages were counted in duplicate for each bird to verify the number of macrophages with phagocytized erythrocytes and the number of phagocytized erythrocytes in each macrophage. The phagocytic activity was calculated by dividing the number of macrophages with phagocytized erythrocytes by the total number of macrophages.

Simultaneously, the same process was conducted with a second plate; however, during the second wash, $200 \mu \mathrm{L}$ of RPMI 1640 was stored per well. The plates were then placed in an incubator for an additional 24 hours to measure nitric oxide production in the macrophages. Each sample contained a positive control $(\mathrm{M} \varnothing+\mathrm{RBC})$ and negative control (MØ), which differed based on the presence or absence of red blood cells (RBC); the negative control represented spontaneous production of nitric oxide in the macrophages (MØ); the positive control represented production of nitric oxide in the macrophages stimulated by the presence of $\mathrm{RBC}(\mathrm{M} \emptyset+\mathrm{RBC})$; and the difference between the positive and negative control was calculated to verify the interaction of both (Mello et al., 2014). After 24 hours, the supernatant was collected and nitrite levels were measured using the Griess reaction (Qureshi et al., 1986). Briefly, 100 microliters of each culture supernatant were incubated in the dark with an equal volume (1:1) of Griess reagent $(1 \%$ sulfanilamide/ 0.1 naphthylenediamine/2.5\% phosphoric acid) in individual wells of a 96-well plate for 15 min. Absorbance was measured at a wavelength of 590 
$\mathrm{n} M$ using an ELISA plate reader. Values were compared with concentrations derived from a standard curve prepared by serial dilution (in RPMI w/o Phenol Red) of a $2 \mathrm{mM}$ sodium nitrite stock solution (Sigma-Aldrich, São Paulo, SP, Brazil). In addition, the difference between the controls was calculated.

The results of the relative weight of lymphoid organs, macrophage activity and antibody titer were analyzed using an analysis of variance and polynomial regression with the software systems analysis and genetic statistics (SAEG) (SSGA; Sistemas de Análises Estatísticas e Genéticas, SAEG) (UFV, 1997). The hematological data were first analyzed using the Shapiro-Wilk test to verify whether the data had a normal distribution. The variables with normal distribution were analyzed using analysis of variance and simple linear regression; the remaining variables were analyzed using generalized linear models, using Gamma distribution with Reverse link function. For the interdigital reaction to phytohemagglutinin, the Shapiro-Wilk test was also performed with variables in normal distribution subjected to analysis of variance and multiple linear regression, which considered the timing and doses of inclusion of propolis residue. Both analyses were performed using R software (R Development Core Team, 2009). A Dunnett's test was used $(\mathrm{p}<0.05)$ to compare the results between control and propolis residue doses. For interdigital reaction to phytohemagglutinin, to assess the effect of time elapsed between the measures, the Tukey test was used $(\mathrm{p}<0.05)$.

\section{RESULTS AND DISCUSSION}

The propolis residue used in this experiment contained $11.46 \mathrm{mg} / \mathrm{kg}$ of total polyphenols and $2.57 \mathrm{mg} / \mathrm{kg}$ of total flavonoids; as expected these values were lower than those presented by crude propolis (Eyng et al., 2013a) and extract derived from crude propolis (Eyng et al., 2013b). Many of the biological effects produced by propolis, such as immunostimulatory action, are related to the presence of these two constituents (Ansorge et al., 2003), which is considered a parameter for measuring the quality of the material.

The inclusion of propolis residue in diets showed a quadratic effect $(\mathrm{p}<0.05)$ on thymus weight, with the lowest weight predicted to occur at a dose of $2.38 \%$; however, the thymus weight of animals fed different amount of propolis residue did not differ from those of animals in the control group. The different doses of propolis residue inclusion had no effect on relative weight of cloacal bursa and spleen of the animals (Table 2). These results are in accordance with the findings of Abioja et al. (2012) who demonstrate effect of the honey only on the size of thymus out of all organs sampled in broiler chickens. The results above suggest that
Table 2. Relative weights $(\%) \pm$ standard error of thymus, cloacal bursa and spleen of broiler chickens at 21 days of age fed diets with different doses of propolis extraction residue

\begin{tabular}{lccc}
\hline $\begin{array}{l}\text { Doses of } \\
\text { propolis residue }\end{array}$ & Thymus & Cloacal bursa & Spleen \\
\hline Control & $0.68 \pm 0.04$ & $0.25 \pm 0.02$ & $0.11 \pm 0.01$ \\
$1 \%$ & $0.63 \pm 0.05$ & $0.24 \pm 0.02$ & $0.14 \pm 0.01$ \\
$2 \%$ & $0.60 \pm 0.04$ & $0.23 \pm 0.02$ & $0.14 \pm 0.01$ \\
$3 \%$ & $0.50 \pm 0.06$ & $0.27 \pm 0.02$ & $0.12 \pm 0.01$ \\
$4 \%$ & $0.72 \pm 0.08$ & $0.27 \pm 0.03$ & $0.16 \pm 0.01$ \\
Regression & Quadratic $^{1}$ & $\mathrm{~ns}$ & $\mathrm{~ns}$ \\
\hline
\end{tabular}

ns, not significant; Not significant by Dunnett test ( $\mathrm{p}>0.05)$.

${ }^{1} \mathrm{Y}=0.890129-0.301205 \mathrm{x}+0.0633504 \mathrm{x}^{2}\left(\mathrm{R}^{2}=0.70\right) ;(\mathrm{p}=0.04) ;$ Minimum point, $2.38 \%$.

lymphoid compartments differ in their responses to propolis residue inclusion in chicken maybe due the different role in immune system. The bursa of Fabricius and spleen are sites of $\mathrm{B}$ cells and $\mathrm{T}$ cells diferentiation, respectively (Cooper et al., 1966). In addition, spleen is the main peripheral lymphoid organ of systemic immunity (John, 1994).

The relative weight of lymphoid organs is often used to predict the immune status of an animal (Abdel-Fattah et al., 2008); changes in weight may be related to alterations in the lymphoid organs' function, and could result in an increased susceptibility to infections or a reduction in the ability of the animal to maintain productivity during a sanitary challenge (Fasina et al., 2006). According to Fan et al. (2013) propolis is able to enhance lymphocyte proliferation, and this can reflect in the lymphoid organs weight, impacting on immune function and disease resistance ability. Although studies reported positive effects on immune organ development with supplementation of propolis and others natural additives (Li et al., 2009; Hegazi et al., 2012), the inclusion of $2.38 \%$ propolis residue on diets resulted in lowest relative thymus weight and may be indicative of impaired immune function (Kwak et al., 1999). Nevertheless, it is important to consider that the lowest weight may not necessarily be related to a lower production of lymphoid cells; therefore, it is necessary to correlate this variable with other measures of immunity status (Kabir et al., 2004; Makram et al., 2010).

With regard to the hematological values and heterophil:lymphocyte $(\mathrm{H}: \mathrm{L})$ ratio, there was a quadratic effect $(p<0.05)$ for the inclusion of propolis residue on the percentage of monocytes, with the lowest percentage reported at $2.49 \%$. However, when each inclusion dose of propolis residue was compared with the control treatment, no difference was observed. The percentage of lymphocyte, heterophil, basophil, and eosinophil and the H:L ratio was not affected by propolis residue inclusion (Table 3 ).

The differential leukocyte count can be used to estimate the impact of dietary additives on the animal's health 
Table 3. Hematological values (\%) and heterophil:lymphocyte ratio (H:L) \pm standard error of broiler chickens at 21 days of age fed diets with different doses of propolis extraction residue

\begin{tabular}{lcccccc}
\hline Doses of propolis residue & Lymphocyte & Heterophil & Basophil & Monocyte & Eosinophil & H:L \\
\hline Control & $62.71 \pm 3.88$ & $22.66 \pm 3.45$ & $8.19 \pm 0.71$ & $1.17 \pm 0.45$ & $5.27 \pm 0.72$ & $0.38 \pm 0.07$ \\
$1 \%$ & $67.97 \pm 2.38$ & $16.66 \pm 1.70$ & $7.67 \pm 0.91$ & $2.08 \pm 0.67$ & $5.61 \pm 0.81$ & $0.25 \pm 0.03$ \\
$2 \%$ & $67.29 \pm 3.18$ & $18.00 \pm 1.66$ & $7.84 \pm 0.16$ & $0.75 \pm 0.42$ & $6.12 \pm 1.66$ & $0.27 \pm 0.03$ \\
$3 \%$ & $68.52 \pm 1.47$ & $17.12 \pm 1.97$ & $9.24 \pm 2.41$ & $0.99 \pm 0.31$ & $4.13 \pm 0.85$ & $0.25 \pm 0.03$ \\
$4 \%$ & $61.39 \pm 4.88$ & $23.02 \pm 4.32$ & $9.00 \pm 2.09$ & $2.12 \pm 0.55$ & $4.46 \pm 0.67$ & $0.41 \pm 0.11$ \\
Regression & $\mathrm{ns}$ & $\mathrm{ns}$ & $\mathrm{ns}$ & Quadratic $^{1}$ & $\mathrm{~ns}$ & $\mathrm{~ns}$ \\
\hline
\end{tabular}

ns, not significant; Not significant by Dunnett test $(\mathrm{p}>0.05)$.

${ }^{1} \mathrm{Y}=-0.8511+1.6755 \mathrm{x}-0.3368 \mathrm{x}^{2}\left(\mathrm{R}^{2}=0.99\right)(\mathrm{p}=0.02)$; Minimum point, $2.49 \%$

(Toghyani et al., 2010). Leukocytes are immune-related cells that are involved in defense of the body against foreign materials and infections, killing virus-infected cells, and enhancing the antibody production (Olugbemi et al., 2010; Salim et al., 2013). In the present assay, it was observed that propolis residue interfered with respect to monocytes; this cell component has an important role in immunity, making them indispensable in phagocytosis and activation of the acquired immune response through the production of cytokines (Konjufca et al., 2004; Liu et al., 2014); however, the interference in the blood monocyte percentage observed is not enough evidence to conclude that the propolis residue impaired immune response.

The nitric oxide production with regard to positive control $(\mathrm{M} \varnothing+\mathrm{RBC})$ decreased linearly $(\mathrm{p}<0.05)$ with increased doses of inclusion propolis residue. However, the nitric oxide production (positive control) of animals fed different amounts of propolis residue did not differ from those of animals in the control group. Changes in phagocytic activity of macrophages, phagocytosed erythrocytes count and nitric oxide production (negative control, and difference between the controls) were not observed (Table 4).

The ability of propolis to activate macrophages has been reported, thereby increasing the release of microbicidal agents, such as nitric oxide, by these cells, and subsequently inducing the production of anti-inflammatory cytokines (Orsi et al., 2000; Sforcin, 2007). However, the results showed a negative linear effect on nitric oxide production in the positive control $(\mathrm{M} \emptyset+\mathrm{RBC})$, demonstrating a lower production of microbicidal agents by these cells. Orsi et al. (2000) suggested that propolis induces nitric oxide production in a dose-dependent manner at high concentrations.

There was no interaction between treatment and time for interdigital reaction to phytohemagglutinin. The analysis of variance indicated that variables were affected $(p<0.05)$ by time elapsed between measurements and the dose of residue inclusion. When each inclusion dose was compared to the control, it was found that birds fed diets containing $1 \%$ of propolis residue had higher $(\mathrm{p}<0.05)$ reaction responses (Table 5). The reaction showed quadratic behavior $(\mathrm{p}<0.05)$ as a function of treatment timing and doses. According to the adjusted equation, birds that were fed with $2.60 \%$ of propolis residue exhibited the least reaction value which is demonstrated by the lower $\mathrm{CBH}$ response to phytohemagglutinin, suggesting that the inclusion of $2.60 \%$ of propolis residue affected negatively the immune response. Also according to the adjusted equation, only after 43.05 hours of the phytohemagglutinin injection the greatest reaction value was observed as demonstrated by the highest $\mathrm{CBH}$ response to phytohemagglutinin at this time.

A time delay in maximum stimulation was observed with the highest value of reaction being reported only 43.05 hours after phytohemagglutinin injection, which suggests that the animals did not have a rapid immunological

Table 4. Phagocytic activity of macrophages (\%), phagocytosed erythrocytes (phagocytosed erythrocytes/macrophage) and nitric oxide concentration $(\mu \mathrm{M} / \mathrm{mL}) \pm$ standard error of broiler chickens at 21 days of age fed diets with different doses of propolis extraction residue

\begin{tabular}{|c|c|c|c|c|c|}
\hline \multirow{2}{*}{$\begin{array}{l}\text { Doses of } \\
\text { propolis residue }\end{array}$} & \multirow{2}{*}{$\begin{array}{l}\text { Phagocytic } \\
\text { activity }\end{array}$} & \multirow{2}{*}{$\begin{array}{c}\text { Phagocytosed } \\
\text { erythrocytes }\end{array}$} & \multicolumn{3}{|c|}{ Nitric oxide } \\
\hline & & & Positive $^{1}$ & Negative $^{2}$ & Positive-negative \\
\hline Control & $19.79 \pm 2.23$ & $5.16 \pm 0.30$ & $12.60 \pm 3.03$ & $6.35 \pm 1.68$ & $6.26 \pm 2.68$ \\
\hline $1 \%$ & $22.75 \pm 2.17$ & $5.44 \pm 0.41$ & $19.13 \pm 3.92$ & $5.97 \pm 1.07$ & $13.16 \pm 3.73$ \\
\hline $2 \%$ & $20.22 \pm 2.06$ & $5.17 \pm 0.30$ & $13.25 \pm 2.46$ & $7.30 \pm 0.63$ & $5.95 \pm 1.84$ \\
\hline $3 \%$ & $18.89 \pm 2.56$ & $4.75 \pm 0.39$ & $10.32 \pm 1.57$ & $5.74 \pm 1.05$ & $4.57 \pm 1.81$ \\
\hline $4 \%$ & $20.00 \pm 2.29$ & $5.44 \pm 0.19$ & $11.67 \pm 0.82$ & $4.23 \pm 1.19$ & $7.43 \pm 0.39$ \\
\hline Regression & ns & ns & Linear $^{3}$ & ns & ns \\
\hline
\end{tabular}

ns, not significant; Not significant by Dunnett test ( $\mathrm{p}>0.05)$.

${ }^{1}$ Positive control $=$ macrophages+erythrocytes. ${ }^{2}$ Negative control $=$ macrophages.

${ }^{3} \mathrm{Y}=20.4041-2.73929 \mathrm{x}\left(\mathrm{R}^{2}=0.74\right)(\mathrm{p}=0.05)$. 
Table 5. Interdigital reaction to phytohemagglutinin $(\mathrm{mm}) \pm$ standard error of broiler chickens at 21 days of age fed diets with different doses of propolis extraction residue

\begin{tabular}{|c|c|c|c|c|c|}
\hline Doses of propolis residue & $12 \mathrm{~h}$ & $24 \mathrm{~h}$ & $48 \mathrm{~h}$ & $72 \mathrm{~h}$ & $\begin{array}{c}\text { Treatment } \\
\text { average }\end{array}$ \\
\hline Control & $0.53 \pm 0.046$ & $0.56 \pm 0.065$ & $0.76 \pm 0.058$ & $0.42 \pm 0.033$ & 0.57 \\
\hline $1 \%$ & $0.69 \pm 0.064$ & $0.96 \pm 0.075$ & $0.96 \pm 0.082$ & $0.76 \pm 0.086$ & $0.84 *$ \\
\hline $2 \%$ & $0.50 \pm 0.093$ & $0.60 \pm 0.081$ & $0.66 \pm 0.099$ & $0.40 \pm 0.093$ & 0.54 \\
\hline $3 \%$ & $0.63 \pm 0.137$ & $0.76 \pm 0.145$ & $0.77 \pm 0.147$ & $0.62 \pm 0.137$ & 0.70 \\
\hline $4 \%$ & $0.44 \pm 0.069$ & $0.81 \pm 0.102$ & $0.92 \pm 0.164$ & $0.75 \pm 0.104$ & 0.73 \\
\hline Time average & $0.56^{\mathrm{c}}$ & $0.74^{\mathrm{ab}}$ & $0.81^{\mathrm{bc}}$ & $0.59^{\mathrm{a}}$ & \\
\hline Treatment & \multicolumn{5}{|c|}{$*$} \\
\hline Time & \multicolumn{5}{|c|}{$*$} \\
\hline Treatment $\times$ time & \multicolumn{5}{|c|}{ ns } \\
\hline Time effect & \multicolumn{5}{|c|}{ Quadratic $^{1}(\mathrm{p}=0.0004)$} \\
\hline Treatment effect & \multicolumn{5}{|c|}{ Quadratic $^{1}(\mathrm{p}=0.002)$} \\
\hline
\end{tabular}

ns, not significant.

Means followed by different letters, in the same row, differ by Tukey test $(\mathrm{p}<0.05)$

${ }^{1} \mathrm{Y}=0.8203+0.02318 \times \mathrm{h}-0.0002692 \times \mathrm{h}^{2}-0.4426 \times \operatorname{dose}+0.08524 \times \operatorname{dose}^{2}\left(\mathrm{R}^{2}=0.69\right)$.

* Means, in the same column, differ from the control by Dunnett test $(\mathrm{p}<0.05)$.

response compared with other studies that have also evaluated $\mathrm{CBH}$ response to phytohemagglutinin in birds (Abd El-Motaal et al., 2008; Galal et al., 2008). Regarding the reduction of reaction over time, this was expected due to the regulation of physiological events with the recruitment of cells which combat foreign agents. The interdigital reaction to phytohemagglutinin involves the stimulation of $\mathrm{T}$ cells; as the thymus is the organ responsible for the maturation of these cells (Moore and Siopes, 2002); the reduction in relative thymus weight presented in this study is consistent with the lower responsiveness to phytohemagglutinin.

Supplementation of propolis residue did not affect the production of serum antibodies against Newcastle disease (Table 6). The antibody level is indicative of specific humoral immunity; thus, the results showed that the addition of propolis residue was not effective for promoting humoral immunity in animals. However, several studies have shown that propolis is capable of providing an increase in immunoglobulin production (Ziaran et al., 2005; Çetin et al., 2010), and can therefore be used as adjuvant in vaccines to increase immunogenicity, thereby making them

Table 6. Antibody titer $\left(\log _{10}\right) \pm$ standard error of broiler chickens at 21 days of age fed diets with different doses of propolis extraction residue

\begin{tabular}{lc}
\hline Doses of propolis residue & Titer \\
\hline Control & $2.45 \pm 0.068$ \\
$1 \%$ & $2.25 \pm 0.080$ \\
$2 \%$ & $2.13 \pm 0.076$ \\
$3 \%$ & $2.23 \pm 0.122$ \\
$4 \%$ & $2.12 \pm 0.053$ \\
Regression & $\mathrm{ns}$ \\
\hline
\end{tabular}

ns, not significant; Not significant by Dunnett test $(\mathrm{p}>0.05)$. more effective with prolonged effects (Fischer et al., 2010). In fact, according to Nassar et al. (2012) propolis can be used as an immunostimulant with human and animal vaccines.

Despite the immunostimulatory action of propolis reported in the literature, deleterious effects of propolis residue were observed for some parameters. Although the residue contained biological compounds (polyphenols and flavonoids) derived from crude propolis the levels used were not enough to enhance the immune responses of broiler chicks.

\section{CONCLUSION}

The inclusion of $1 \%$ to $4 \%$ of propolis extraction residue in broiler diets from 1 to 21 days of age was not able to improve the immune parameters, despite the modest changes in the relative weight in thymus, blood monocyte percentage, nitric oxide concentration, and $\mathrm{CBH}$ response to phytohemagglutinin. Further investigations with other doses of inclusion are needed to assess the optimal dose of propolis residue that could promote immunostimulatory activity.

\section{REFERENCES}

Abd El-Motaal, A. M., A. M. H. Ahmed, A. S. A. Bahakaim, and M. M. Fathi. 2008. Productive performance and immunocompetence of commercial laying hens given diets supplemented with eucalyptus. Int. J. Poult. Sci. 7:445-449.

Abdel-Fattah, S. A., M. H. El-Sanhoury, N. M. El-Mednay, and F. Abdel-Azeem. 2008. Thyroid activity, some blood constituents, organs morphology and performance of broiler chicks fed supplemental organic acids. Int. J. Poult. Sci. 7:215-222. 
Abioja, M. O., K. B. Ogundimu, T. E. Akibo, K. E. Odukoya, O. O. Ajiboye, J. A. Abiona, T. J. Williams, E. O. Oke, and O. A. Osinowo. 2012. Growth, mineral deposition, and physiological responses of broiler chickens offered honey in drinking water during hot-dry season. Int. J. Zool. Article ID 403502. doi: $10.1155 / 2012 / 403502$.

Apata, D. F. 2009. Antibiotic resistance in poultry. Int. J. Poult. Sci. 8:404-408.

Ansorge, S., D. Reinhold, and U. Lendeckel. 2003. Propolis and some of its constituents down-regulate DNA synthesis and inflammatory cytokine production but induce TGF- $\beta 1$ production of human immune cells. Z. Naturforsch. 58:580589.

Casewell, M., C. Friis, E. Marco, P. McMullin, and I. Phillips. 2003. The European ban on growth-promoting antibiotics and emerging consequences for human and animal health. J. Antimicrob. Chemother. 52:159-161.

Çetin, E., S. Silici, N. Çetin, and B. K. Güçlü. 2010. Effects of diets containing different concentrations of propolis on hematological and immunological variables in laying hens. Poult. Sci. 89:1703-1708.

Cooper, M. D., D. A. Raymond, R. D. Peterson, M. A. South, and R. A. Good. 1966. The functions of the thymus system and the bursa system in the chicken. J. Exp. Med. 123:75-102.

Corrier, D. E. and J. R. Deloach. 1990. Evaluation of cellmediated, cutaneous basophil hypersensitivity in young chickens by an interdigital skin test. Poult. Sci. 69:403-408.

Eyng, C., A. E. Murakami, R. B. Pedroso, T. G. V. Silveira, D. A. L. Lourenço, and A. F. Q. M. Garcia. 2013a. Crude propolis as an immunostimulating agent in broiler feed during the starter phase. Semina: Ciências Agrárias 34:2511-2522.

Eyng, C., A. E. Murakami, C. R. A. Duarte, and T. C. Santos. 2013b. Effect of dietary supplementation with an ethanolic extract of propolis on broiler intestinal morphology and digestive enzyme activity. J. Anim. Physiol. Anim. Nutr. 98:393-401.

Fan, Y., L. Yu, W. Deyun, J. Liu, X. Song, W. Zhang, X. Zhao, T. L. Nguyen, and Y. Hu. 2013. Effect of epimedium polysaccharide-propolis flavone immunopotentiator on immunosuppression induced by cyclophosphamide in chickens. Cell. Immunol. 281:37-43.

Fasina, Y. O., H. L. Classen, J. D. Garlich, B. L. Black, P. R. Ferket, Z. Uni, and A. A. Olkowski. 2006. Response of Turkey poults to soybean lectin levels typically encountered in commercial diets. 2. Effect on intestinal development and lymphoid organs. Poult. Sci. 85:870-877.

Fischer, G., N. Paulino, M. C. Marcucci, B. S. Siedler, L. S. Munhoz, P. F. Finger, G. D. Vargas, S. O. Hübner, T. Vidor, and P. M. Roehe. 2010. Green propolis phenolic compounds act as vaccine adjuvants, improving humoral and cellular responses in mice inoculated with inactivated vaccines. Mem. Inst. Oswaldo Cruz 105:908-913.

Galal, A., A. M. Abd El-Motaal, A. M. H. Ahmed, and T. G. Zaki. 2008. Productive performance and immune response of laying hens as affected by dietary propolis supplementation. Int. J. Poult. Sci. 7:272-278.

Hegazi, A., A. M. Abdou, and F. A. Allah. 2012. Egyptian propolis 9- Its effect on chicken productivity and immune response against Newcastle disease vaccine. Br. Poult. Sci. 3:25-30.

Hu F., H. R. Hepburn, Y. Li, M. Chen, S. E. Radloff, and S. Daya. 2005. Effects of ethanol and water extracts of propolis (bee glue) on acute inflammatory animal models. J. Ethnopharmacol. 100:276-83.

John, J. L. 1994. The avian spleen: A neglected organ. Q. Rev. Biol. 69:327-351.

Kabir, S. M. L., N. M. Rahman, M. B. Rahman, M. M. Rahma, and S. U. Ahmed. 2004. The dynamics of probiotics on growth performance and immune response in broilers. Int. J. Poult. Sci. $3: 361-364$.

Konjufca, V. K., W. G. Bottje, T. K. Bersi and G. F. Erf. 2004. Influence of dietary Vitamin $\mathrm{E}$ on phagocytic functions of macrophages in broilers. Poult. Sci. 83:1530-1534.

Kosalec I., S. Pepeljnjak, M. Bakmaz and S. Vladimir-Knezevic. 2005. Flavonoid analysis and antimicrobial activity of commercially available propolis product. Acta Pharm. 55:423430.

Kwak, H., R. E. Austic, and R. R. Dietert. 1999. Influence of dietary arginine concentration on lymphoid organ growth in chickens. Poult. Sci. 78:1536-1541.

Liu, X., J. A. Byrd, M. Farnell, and C. A. Ruiz-Feria. 2014. Arginine and vitamin E improve the immune response after a Salmonella challenge in broiler chicks. Poult. Sci. 93:882-890.

Lofty, M. 2006. Biological activity of bee propolis in health and disease. Asian Pac. J. Cancer. Prev. 7:22-31.

Lucas, A. M. and C. Jamroz. 1961. Atlas of Avian Hematology. U.S. Department of Agriculture, Washington, DC, USA.

Makram, A., A. Galal, M. M. Fathi, and A. H. El-Attar. 2010. Carcass characteristics and immunocompetence parameters of four commercial broiler strain chickens under summer season of Egypt. Int. J. Poult. Sci. 9:171-176.

Moore, C. B. and T. D. Siopes. 2002. Effect of melatonin supplementation on the ontogeny of immunity in the large white turkey poult. Poult. Sci. 81:1898-1903.

Nassar, S. A., A. H. Mohamed, H. Soufy, S. M. Nasr, and K. M. Mahran. 2012. Immunostimulant effect of Egyptian propolis in rabbits. Sci. World J. Article ID 901516 doi:10.1100/2012/901516

Olugbemi, T. S., S. K. Mutayoba, and F. P. Lekule. 2010. Effect of Moringa (Moringa oleifera) inclusion in cassava based diets fed to broiler chickens. Int. J. Poult. Sci. 9:363-367.

Orsi, R. O., S. R. C. Funari, A. M. V. C. Soares, S. A. Calvi, S. L. Oliveira, J. M. Sforcin, and V. Bankova. 2000. Immunomodulatory action of propolis on macrophage activation. J. Venom. Anim. Toxins Incl. Trop. Dis. 6:205-219.

Pierpoint, W. S. 2004. The extraction of enzymes from plant tissues rich in phenolic compounds. Methods Mol. Biol. 244:65-74.

Qureshi, M. A., R. R. Dieteri, and L. D. Bacon. 1986. Genetic variation in the recruitment and activation of chicken peritoneal macrophages. Proc. Soc. Exp. Biol. Med. 181:560568.

R Development Core Team. 2007. Statistical Computing. R Foundation for Statistical Computing. Vienna, Austria.

Rostagno, H. S., L. F. T. Albino, J. L. Donzele, P. C. Gomes, R. F. Oliveira, D. C. Lopes, A. S. Ferreira, and S. L. T. Barreto. 2005. Brazilian Tables for Poultry and Swine: Composition of 
Feedstuffs and Nutritional Requirements. Viçosa, MG: UFV, Departamento de Zootecnia, Brazil. 186 p.

SAEG. 1997. Statistical Analysis System and Genetics - SAEG. Stat. version 8.0. Universidade Federal de Viçosa, Viçosa, Minas Gerais, Brazil.

Salatino, A., C. C. Fernandes-Silva, A. A. Righi, and M. L. F. Salatino. 2011. Propolis research and the chemistry of plant products. Nat. Prod. Rep. 28:925-936.

Salim, H. M., H. K. Kang, N. Akter, D. W. Kim, J. H. Kim, M. J.
Kim, J. C. Na, H. B. Jong, H. C. Choi, O. S. Suh, and W. K. Kim. 2013. Supplementation of direct-fed microbials as an alternative to antibiotic on growth performance, immune response, cecal microbial population, and ileal morphology of broiler chickens. Poult. Sci. 92:2084-2090.

Schnitzler, P., A. Neuner, S. Nolkemper, C. Zundel, H. Nowack, K. H. Sehsch, and J. Reichling. 2010. Antiviral activity and mode of action of propolis extracts and selected compounds. Phytother. Res. 24:S20-S28.

Sforcin, J. M. 2007. Propolis and the immune system: A review. J. Ethnopharmacol. 113:1-14.

Shalmany, S. K. and M. Shivazad. 2006. The effect of diet propolis supplementation on ross broiler chicks performance. Int. J. Poult. Sci. 5:84-88
Singleton, V. L. and J. A. Rossi Jr. 1965. Colorimetry of total phenolics whit phosphomolybdic-phosphotungstic acid reagents. Am. J. Enol. Vitic. 16:144-158.

Toghyani, M., M. Tohidi, A. A. Gheisari, and S. A. Tabeidian. 2010. Performance, immunity, serum biochemical and hematological parameters in broiler chicks fed dietary thyme as alternative for an antibiotic growth promoter. Afr. J. Biotechnol. 9:6819-6825.

Trusheva, B., M. Popova, V. Bankova, S. Simova, M. C. Marcucci, P. L. Miorin, F. R. Pasin, and I. Tsvetkova. 2006. Bioactive constituents of Brazilian red propolis. Evid. Based Complement. Alternat. Med. 3:249-254.

Wagh, V. D. 2013. Propolis: A wonder bees product and its pharmacological potentials. Adv. Pharmacol. Sci. Article ID 308249 doi: $10.1155 / 2013 / 308249$.

Woisky, R. G. and A. Salatino. 1998. Analysis of propolis: some parameters and procedures for chemical quality control. J. Agric. Res. 37:99-105.

Ziaran, H. R., H. R. Rahmani, and J. Pourreza. 2005. Effect of dietary oil extract of propolis on immune response and broiler performance. Pak. J. Biol. Sci. 8:1485-1490. 